\title{
Does Living On-Reserve Versus Off-Reserve Make a Difference in First Nations Birth Outcomes in Manitoba, Canada?
}

\author{
Maureen Heaman*,1, Patricia Martens ${ }^{2}$, Lyna Hart ${ }^{3}$, Janet Smylie ${ }^{4}$, Elizabeth Agnew ${ }^{5}$, \\ Fabienne Simonet ${ }^{6}$, Spogmai Wassimi ${ }^{6}$, William D. Fraser ${ }^{6}$ and Zhong-Cheng Luo ${ }^{6}$
}

\author{
${ }^{1}$ Faculty of Nursing, University of Manitoba, Winnipeg, Canada \\ ${ }^{2}$ Manitoba Centre for Health Policy, Department of Community Health Sciences, University of Manitoba, Winnipeg, \\ Canada \\ ${ }^{3}$ Southeast Resource Development Council Corporation, Winnipeg, Canada \\ ${ }^{4}$ Centre for Research on Inner City Health, St. Michael's Hospital, Department of Public Health Sciences, University of \\ Toronto, Toronto, Canada \\ ${ }^{5}$ St. Boniface General Hospital, Winnipeg, Canada \\ ${ }^{6}$ Department of Obstetrics and Gynecology, Sainte-Justine Hospital, University of Montreal, Montreal, Canada
}

\begin{abstract}
Objective: First Nations people in Canada often migrate between living "on-reserve" and "off-reserve." The purpose of this study was to determine if there was any difference in birth outcomes among First Nations women living on-reserve versus off-reserve in Manitoba.

Study Design: This population-based birth cohort study was conducted using Statistics Canada's linked vital data for Manitoba, 1991-2000. A total of 26,176 First Nation births were identified (14,165 on-reserve, 12,011 off-reserve), based on self reporting by the mother or father. A mother was considered to be living on-reserve if her residential postal code (or municipal code) was among those used for First Nations bands or communities.

Results: The crude rates of preterm (7.5\% versus $9.7 \%)$ and small-for-gestational-age $(7.3 \%$ versus $8.1 \%)$ births were significantly lower among First Nations women living on-reserve compared to off-reserve, while rates of neonatal death (4.1 versus 4.1 per 1,000$)$ and postneonatal death $(6.6$ versus 5.6 per 1,000) were not significantly different. After adjusting for maternal characteristics and rural versus urban residence, the lower risks of preterm birth (adjusted odds ratio [aOR] 0.82 [95\% confidence interval [CI] 0.75-0.90]) and small-for-gestational-age (aOR 0.89 [0.81-0.98]) on-reserve remained, but a higher risk of infant death was observed (aOR 1.29, 95\% CI 1.00-1.67) mostly due to higher risk of postneonatal death.

Conclusion: Living off-reserve is associated with higher rates of preterm and small-for-gestational-age births, suggesting the need to improve prenatal care. Living on-reserve is associated with higher rates of infant death, suggesting the need to improve infant care and socioeconomic conditions.
\end{abstract}

Keywords: Aboriginal, Native American, pregnancy, birth out comes, preterm birth, infant death.

\section{INTRODUCTION}

In 2001, 976,305 Canadians $(3.3 \%$ of the total population) self-identified as an Aboriginal person; this count was $22.2 \%$ higher than the 1996 Figure of 799,010 [1]. The growing population of Aboriginal people living in Canada is linked to a birth rate that is 1.5 times higher than the Canadian rate [1]. In 2001, $62 \%$ of Aboriginal people identified as First Nations (North American Indian), making this the largest Aboriginal group in the country [1]. First Nations people include status Indians (registered under the Indian Act) and non-status Indians. In 2001, there were 90,155 status Indians

*Address correspondence to this author at the Faculty of Nursing, Room 268 Helen Glass Centre for Nursing, 89 Curry Place, University of Manitoba, Winnipeg, Manitoba, R3T 2N2, Canada; Tel: 1-204-474-6222;

Fax: 1-204-474-6013; E-mail: maureen_heaman@umanitoba.ca in the province of Manitoba, up 10.3\% from 1996 [2]. The majority $(56 \%)$ of First Nations people in Manitoba live on Indian reserves ("on-reserve", mainly in rural and northern areas), while $24 \%$ live in the capital city of Winnipeg (in the southernmost part of the province), and $20 \%$ live elsewhere in the province, mainly in smaller urban centers [2]. An Indian reserve is legally defined in the Indian Act as a tract of land set aside for the use and benefit of an Indian Band or First Nation [3]. Fig. (1) is a map of First Nations reserves in Manitoba.

The urban Aboriginal population of Canada has experienced extensive growth since the 1960s. It is sometimes erroneously thought that this growth is mainly due to migration of First Nations people from reserve communities to cities in order to find employment or to escape poor social conditions [4]. However, more recent studies have shown that reserves have been net gainers of migrants, with more 


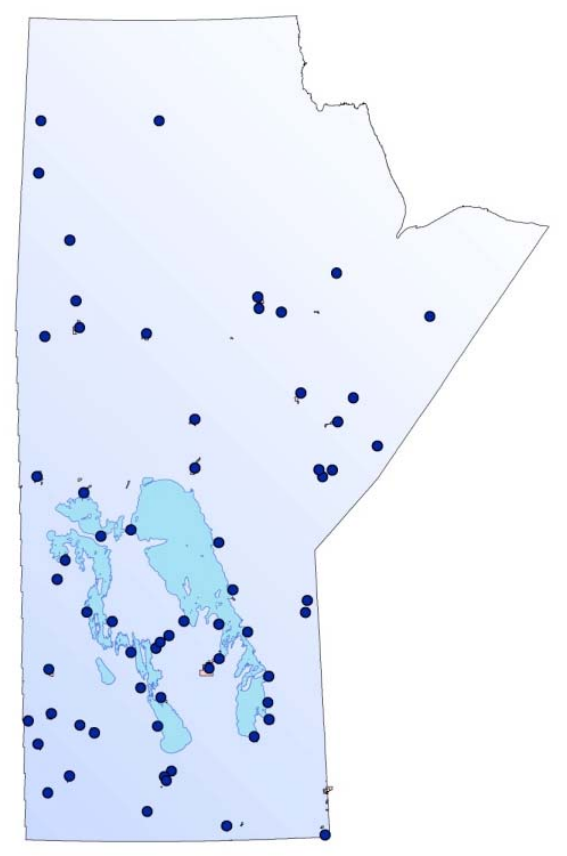

Fig. (1). Map of the Province of Manitoba Indicating Location of First Nations Reserves (Map created by Mr. Charles Burchill, Manitoba Centre for Health Policy, 2009, and reproduced with permission).

Registered First Nations people moving from cities to reserves as opposed to movement in the opposite direction [5]. Between 1991 and 1996, 27 percent of Registered First Nations people moved to the city of Winnipeg from reserves, while 47 percent of Registered First Nations people left Winnipeg and moved to reserves [3]. Between 1996 and 2001, Winnipeg and on-reserve locations had a small net inmigration of First Nations people at the expense of offreserve areas outside Winnipeg; and there was little change in the population of any area due to migration [2].

The tendency to migrate between cities and reserves is often described in terms of push-pull factors. Examples of "push" factors from reserves include lack of employment opportunities, poor economic and social conditions, and lack of housing, health facilities, and educational opportunities on-reserve [3,4]. Corresponding "pulls" to the city include better opportunities for education and employment [4], as well as the "bright lights" in the case of young adults [3]. "Pulls" to reserves are described in terms of their roles as a home base and "cultural hearth" to which return is relatively easy, providing a network of friends, family and culturally appropriate supports and services that many not be available off reserve [3]. Unfortunately return migration of Registered Indians from cities to reserves is often described as failure to integrate into an urban environment resulting from the inability of securing employment, discrimination, and a lack of access to affordable housing [5].

Personal characteristics also have a role in migration demographics. Migration in, migration out and net migration between cities and reserves is highest among young adults aged 19-25 [5], which can be explained partly in terms of life-cycle stages. Other consistent findings demonstrate that rates of migration from reserves to cities are higher among young women, while rates of migration from the cities to reserves are higher among young men $[3,5]$. Young men tend to be economically motivated to move while young women are typically motivated by evolving family contexts such as seeking to improve educational opportunities or health care for their children [5]. First Nations women experiencing domestic violence may also leave their community and travel to an urban centre to escape abuse and access a shelter $[4,6]$.

Birth outcomes are persistently worse among Aboriginal compared to non-Aboriginal populations in developed countries, with rates of stillbirth, infant mortality, low-birthweight infants, high-birth-weight infants and prematurity being higher among infants born to Aboriginal or Indigenous women [7-16]. Some of these studies have focused specifically on birth outcomes for First Nations women compared to the rest of the population. Infant mortality rates have been shown to be twice as high among First Nations versus nonFirst Nations in both rural and urban areas [9]. Significantly higher risks of postneonatal death due to sudden infant death syndrome (SIDS), infection and external causes have been shown in First Nations populations, with SIDS accounting for approximately 50 percent of postneonatal deaths [10]. First Nations infants have also been shown to have shorter gestations with heavier birth weights [9].

A few studies have explored whether urban versus rural residence affects the disparities in birth outcomes among Aboriginal and non-Aboriginal populations. A recent Australian study found that the disparity in infant mortality comparing Aboriginal versus non-Aboriginal populations was larger in remote rural areas [8]. Among North American Indians and Alaskan Natives compared to Whites in the United States, greater disparities in infant mortality have been reported in some urban areas than those observed in rural areas [12]. In the Canadian province of British Columbia, the disparity in infant mortality comparing First Nations to nonFirst Nations declined less substantially and less consistently in urban versus rural areas [9]. However, to our knowledge, no studies have compared birth outcomes among First Nations women living on-reserve and off-reserve. This study proposes to address this gap using data from the province of Manitoba.

\section{STUDY DESIGN}

We conducted a retrospective, population-based birth cohort study of all First Nations live births in Manitoba between 1991-2000, using Statistics Canada's linked stillbirth, live birth and infant death database. The validity of the Canadian linked vital data has been well documented [17]. A birth was considered a First Nations birth if the mother or father self-identified as First Nations by checking "Registered Indian" or writing in a treaty number or band name on the live birth registration; $89 \%$ of births were classified based on the maternal identifier. We excluded births $(0.5 \%)$ with missing birth weight, gestational age, or sex, or missing maternal place of residence (postal code and municipal code). Births at gestational age $<20$ weeks or birth weight $<500$ grams were also excluded because the registration of births at the borderline of viability varied substantially [18]. Using the postal code of the mother's usual place of residence as reported on the birth registration, or the place name-based municipal code if the postal code was not available $(<5 \%)$, births were assigned to the corresponding census subdivision and designated as either an Indian Reserve 
("on-reserve") or any other area ("off-reserve"). A total of 26,176 First Nations live births were identified in Manitoba between 1991 and $2000(14,165$ to mothers living on-reserve and 12,011 to mothers living off-reserve).

Maternal and pregnancy characteristics studied included maternal age $(<20,20-34, \geq 35$ years of age), marital status (married or unmarried), parity (primiparous, multiparous), urban (in any census metropolitan area or census agglomeration, with population $>=10,000$ ) versus rural (all other areas) residence, plurality (singleton, multiple births), infant sex (male, female), gestational age (in completed weeks), and birth weight (in grams). Birth outcomes examined included preterm birth (gestational age $<37$ completed weeks), smallfor-gestational-age $\left(<10^{\text {th }}\right.$ percentile, based on the Canadian standard [18]), low birth weight ( $<2500$ grams), high birth weight ( $>4000$ grams), large-for-gestational-age birth $\left(>90^{\text {th }}\right.$ percentile), neonatal death (0-27 days), postneonatal death (28-364 days) and total infant death (0-364 days). Causes of infant death were investigated according to the classification of the International Collaborative Effort on Perinatal and Infant Mortality [20], which was based on the International Classification of Diseases (ICD)-9 codes for deaths in 19911999 or ICD-10 codes for deaths in 2000-2001. Four major causes of death were studied: congenital anomalies, immaturity-related conditions, neonatal asphyxia, and sudden infant death syndrome (SIDS). Analysis of the risk of infant death due to asphyxia was restricted to the neonatal period because such deaths occurred almost exclusively during that period. Analyses of the risk of SIDS were restricted to the postneonatal period as SIDS rarely occurs in the neonatal period [21].

Crude relative risks (RR) and adjusted odds ratios (aOR) with $95 \%$ confidence intervals (CI) were computed to assess the associations between place of residence (on-reserve versus off-reserve) and birth outcomes. The aORs were assessed using multilevel logistic regression analyses. All data management and analyses were carried out using SAS for Windows, Version 9.0 (SAS Institute: Cary, North Carolina).

Research ethics board approval was obtained from Sainte-Justine Hospital of the University of Montreal. The study was approved by the Assembly of Manitoba Chiefs Health Information Research Governance Committee.

\section{RESULTS}

\section{Maternal Characteristics}

Table 1 compares the characteristics of First Nations births to mothers living on- and off-reserve in Manitoba. The majority $(71 \%)$ of First Nations births, whether the mother resided on- or off-reserve, were to mothers between the ages of 20-34 years. Mothers living on-reserve were more likely to be under 20 years of age, while mothers living off-reserve were more likely to be 35 years of age and over. Mothers living off-reserve were more likely to be unmarried than mothers living on reserve ( $82 \%$ versus $68 \%$ ). Mothers living off-reserve were also somewhat more likely to be primiparous than their on-reserve counterparts (30\% versus $28 \%$ ). Comparing First Nations births to mothers living on- versus off-reserve, there was no significant difference in infant sex or the proportion of singleton and multiple births.

\section{Adverse Birth Outcomes}

Table 2 presents the crude rates and relative risk (RR) of adverse birth outcomes for infants born to First Nations mothers living on- and off-reserve. The preterm birth rate showed the most notable difference between the two groups, with $7.5 \%$ of infants born to First Nations mothers living onreserve being preterm compared to $9.7 \%$ of those living offreserve (Fig. 2). First Nations births to women living onreserve were $23 \%$ less likely to be preterm, $10 \%$ less likely to be small-for-gestational-age, and $23 \%$ less likely to be low birth weight than First Nations births to women living offreserve. Conversely, First Nations infants born to women living on-reserve were 5\% more likely to be of high birth weight and $8 \%$ more likely to be large-for-gestational age compared to their off-reserve counterparts. Twenty percent of First Nations births to mothers living on-reserve weighed more than 4000 grams at birth compared to $19 \%$ of First Nations births to mothers living off-reserve, while $18 \%$ of infants in the on-reserve group were large-for-gestationalage compared to $17 \%$ of off-reserve infants. The rates of neonatal death to First Nations infants were identical between mothers living on-reserve and off-reserve (4.1 deaths per 1000 infants for both groups). First Nations infants born to mothers living on-reserve had higher rates of postneonatal death $(6.6 \%$ versus $5.6 \%)$ and infant death $(10.7 \%$ versus 9.6\%) than did First Nations infants born to mothers living off-reserve, but these differences were not statistically sig-

Table 1. Maternal and Infant Characteristics for First Nations Births by Place of Residence, On-Reserve and Off-Reserve in Manitoba, 1991-2000

\begin{tabular}{|c|c|c|c|}
\hline Characteristics & $\begin{array}{c}\text { On-reserve }^{\S} \\
(\mathrm{N}=14,165) \\
(\%)\end{array}$ & $\begin{array}{c}\text { Off-reserve } \\
(\mathrm{n}=12,011) \\
(\%)\end{array}$ & P-value for the difference \\
\hline Infant sex, male & 51.3 & 50.9 & 0.44 \\
\hline Primiparous & 27.7 & 30.4 & $<0.0001$ \\
\hline Maternal age (y) & & & 0.03 \\
\hline$<20$ & 25.0 & 23.7 & \\
\hline$\geq 35$ & 4.5 & 4.9 & \\
\hline Unmarried & 68.3 & 81.6 & $<0.0001$ \\
\hline Urban & 4.3 & 77.5 & $<0.0001$ \\
\hline
\end{tabular}

${ }^{\S} \mathrm{A}$ birth was considered a birth from mothers of on-reserve communities if maternal residential postal codes or census subdivision were those of First Nations communities. 
Table 2. Crude Rates of Adverse Birth Outcomes for First Nations Births by Maternal Place of Residence On-Reserve versus Off-Reserve, Manitoba, 1991-2000

\begin{tabular}{|c|c|c|c|}
\hline Outcome & \multicolumn{2}{|c|}{ First Nations } & $\mathbf{R R}(95 \% \mathrm{CI})$ \\
\hline All births, $n$ & 14,165 & 12,011 & \\
\hline Small-for-gestational-age birth (\%) & 7.3 & 8.1 & $0.90(0.83,0.98) * *$ \\
\hline Low birth weight birth (\%) & 4.6 & 5.9 & $0.77(0.70,0.86)^{*}$ \\
\hline High birth weight birth (\%) & 20.0 & 19.1 & $1.05(1.00,1.10)^{*}$ \\
\hline Postneonatal death (per 1000) & 6.6 & 5.6 & $1.18(0.87,1.61)$ \\
\hline Infant death (per 1000) & 10.7 & 9.6 & $1.11(0.88,1.40)$ \\
\hline \multicolumn{4}{|l|}{ Major causes: } \\
\hline Congenital anomalies & 3.2 & 2.6 & $1.26(0.80,1.98)$ \\
\hline Immaturity-related & 0.8 & 0.9 & $0.93(0.41,2.10)$ \\
\hline Neonatal asphyxia & 0.6 & 0.3 & $1.70(0.51,5.63)$ \\
\hline Sudden Infant Death Syndrome & 1.7 & 1.8 & $0.93(0.52,1.65)$ \\
\hline
\end{tabular}

${ }^{s}$ Maternal place of residence was designated "on- reserve" if maternal residential postal codes or census subdivision were those of First Nations communities.

$* \mathrm{P}<0.05 ; \mathrm{RR}=$ risk ratio; $\mathrm{Cl}=$ confidence interval.

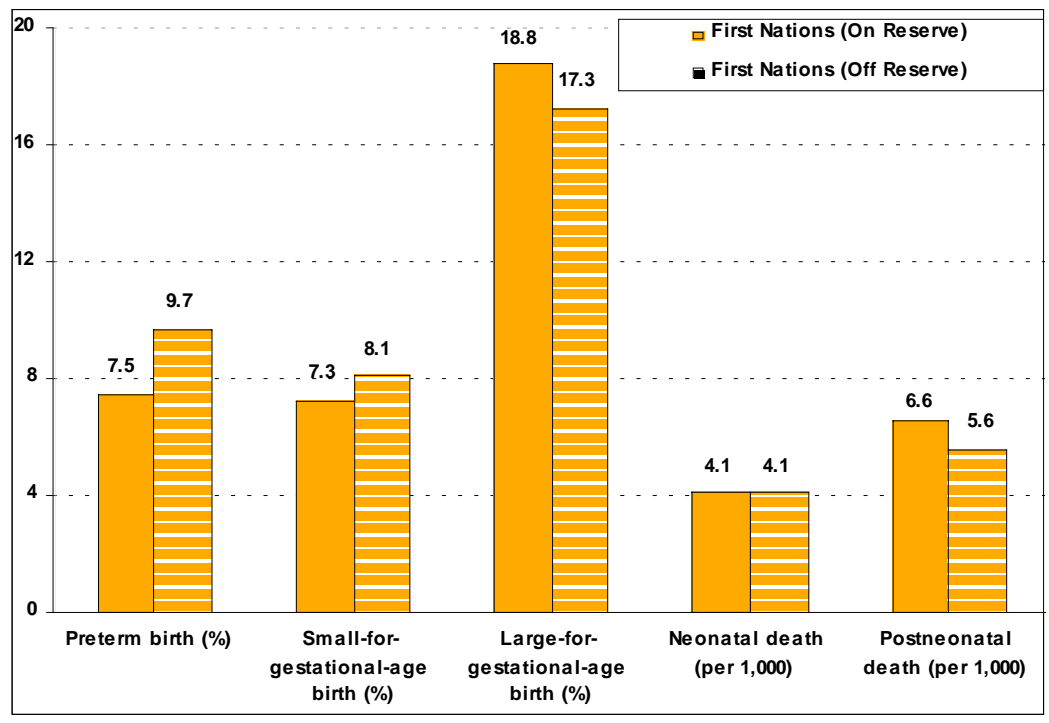

Fig. (2). Crude Rates of Adverse Outcomes for First Nations Births, by Maternal Place of Residence On-Reserve versus Off-Reserve, Manitoba, 1991-2000.

nificant. There were no significant differences in the major causes of infant death between the two groups.

\section{Adjusted Odds Ratios}

With the exception of infant death, crude and adjusted odds ratios (aOR) showed generally similar patterns in the likelihood of adverse birth outcomes to First Nations infants comparing mothers living on- and off-reserve (Table 3). After adjusting for maternal age, marital status, parity, infant sex, multiple pregnancy, and rural versus urban residence, the lower likelihood of preterm birth (aOR 0.82), small-forgestational-age (aOR 0.89) and low birth weight birth (aOR 0.78 ) for those living on-reserve remained, as did the higher likelihood of large-for-gestational-age birth (aOR 1.09). There was no statistically significant difference in the crude likelihood of neonatal death or postneonatal death between the two groups, but after adjustment, the likelihood of infant death was marginally significantly higher $(\mathrm{p}=0.05)$ for First
Nations births among women living on-reserve compared to off-reserve.

\section{DISCUSSION}

Our study reveals significant differences in birth outcomes to First Nations infants born to women living onreserve versus off-reserve. The risk of preterm, small-forgestational-age and low birth weight birth was lower whereas the risk of large-for- gestational-age and high birth weight was higher among First Nations infants born to women living on-reserve compared to off-reserve. Another important difference is that the likelihood of infant death among First Nations infants born to women living on-reserve is marginally higher than for those living off-reserve, primarily due to higher rates of postneonatal death. The reasons for these differences in birth outcomes are not entirely understood, although differences in access to health care, availability of social support, levels of stress, health behaviors, nutritional status, and living conditions among First Nations 
Table 3. Crude and Adjusted Odds Ratios of Adverse Birth Outcomes for First Nations Births by Maternal Place of Residence On-Reserve versus Off-Reserve, Manitoba, 1991-2000

\begin{tabular}{|l|c|c|}
\hline \multicolumn{1}{|c|}{ Outcome } & $\begin{array}{c}\text { Crude OR } \\
\text { (95\% CI) }\end{array}$ & $\begin{array}{c}\text { Adjusted OR }^{\S} \\
(\mathbf{9 5 \%} \text { CI) }\end{array}$ \\
\hline \hline Preterm birth & $0.82(0.75,0.89)^{* *}$ & $0.82(0.75,0.90)^{* *}$ \\
Small-for-gestational-age birth & $0.86(0.78,0.94)^{* *}$ & $0.89(0.81,0.98)^{* *}$ \\
Low birth weight & $0.77(0.69,0.86)^{* *}$ & $0.78(0.70,0.88)^{* *}$ \\
High birth weight & $1.06(1.00,1.13)^{* *}$ & $1.03(0.96,1.09)$ \\
Large-for-gestational-age birth & $1.14(1.07,1.21)^{* *}$ & $1.09(1.02,1.16)^{* *}$ \\
Neonatal death & $1.23(0.82,1.84)$ & $1.26(0.83,1.92)$ \\
Postneonatal death & $1.22(0.88,1.67)$ & $1.31(0.95,1.81)$ \\
Infant death & $1.22(0.95,1.57)$ & $1.29(1.00,1.67)^{*}$ \\
\hline
\end{tabular}

${ }^{\S}$ The adjusted ORs were controlled for infant sex, maternal age $(<20,20-34,35+)$, marital status (married, not married), parity (primiparous or multiparous), multiple pregnancy (singleton or multiple), and rural versus urban residence.

$* \mathrm{P}=0.05 * * \mathrm{P}<0.05$

women living on- and off-reserve may offer some explanations. Risk factors for adverse pregnancy outcomes such as smoking, consuming alcohol, illicit drug use, and poor nutrition are higher among some populations of First Nations women compared to non-First Nations women [14, 22, 23], but the extent to which these behaviors differ among First Nations women living on- and off-reserve is unknown.

Significant modifiable risk factors for preterm birth among Aboriginal women in Manitoba include inadequate prenatal care, poor weight gain during pregnancy, and high levels of perceived stress [24]. A significantly higher proportion of Aboriginal women (15.7\%) than non-Aboriginal women $(3.6 \%)$ in Manitoba have been shown to receive inadequate prenatal care; $80 \%$ of the Aboriginal participants in this study were First Nations women [25]. Perhaps First Nations women living on-reserve receive more prenatal care than their off-reserve counterparts, due to easier access to prenatal care (particularly at nursing stations on northern reserves) and the availability of community health representatives and traditional healers, contributing to their lower risk of preterm birth. In Hiebert's (2001) study of use of prenatal services by First Nations women in four northern Manitoba reserves, most women received an optimal level of prenatal care. On average, the women first came to the nursing station in the ninth week of pregnancy and saw the health care provider ten times for routine visits. In addition, being married was a positive predictor of early initiation of prenatal care [26].

First Nations women living on-reserve may receive more social support from their mother and extended family compared to First Nations women living off-reserve. Reserves have been referred to as "cultural hearths" in that they provide friends, extended family support and culturally appropriate activities and services that may not be available offreserve [3]. Smith and colleagues also suggest that the emotional dimension of safety plays a crucial role in access to prenatal care and the extent to which one feels safe in health care is affected by past experiences. One's willingness to engage in healthcare encounters is also influenced by peer and social network views about how likely organizations and providers are to be safe and caring [27]. Thus women may be more likely to get prenatal care within their home communities as providers are familiar to them, and their peers or members of their social networks may have had positive experiences with these providers. Conversely, First Nations women living off-reserve may be at higher risk of preterm birth related to poor utilization of prenatal care, possibly due to lack of knowledge of where to obtain prenatal care services in an urban area, difficulty finding a physician, lack of culturally appropriate services, and services not provided in their language. First Nations women living off-reserve are more likely to be unmarried, which may result in less social support and higher levels of stress due to isolation, being transient, and living in poverty. Aboriginal people in urban areas tend to live in older and often deficient housing and have greater difficulty finding suitable housing because of discrimination as well as lower average incomes than other Canadians [3]. The priority for these women might be on securing safe, affordable housing instead of obtaining prenatal care. Poverty may also be associated with food security issues and lower weight gain during pregnancy, contributing to higher rates of preterm birth and low birth weight among First Nations women living off-reserve. Conversely, First Nations births to women living on-reserve had higher rates of large-for-gestational-age and high birth weight births. Maternal nutritional status and glycemic status have been associated with macrosomia (birth weight $>4000$ grams) in First Nations women [28]. From 1985 to 2004, the prevalence of gestational diabetes mellitus in First Nations women in Manitoba was three times higher than in non-First Nations women, and there was a higher prevalence of gestational diabetes mellitus in First Nations women living in rural areas compared to those in urban areas [29]. Rates of macrosomia were elevated in Manitoba mothers with gestational diabetes mellitus, type 2 diabetes mellitus, and First Nations status [30]. Therefore strategies to manage glycemic status, prevent obesity, and promote healthy nutrition and appropriate weight gain in First Nations women during pregnancy may be helpful in reducing rates of macrosomia.

Differences in rates of neonatal and postneonatal death were not statistically significant among First Nations births to mothers living on- and off-reserve, although there was a trend to higher rates of postneonatal death among infants born to mothers living on-reserve, contributing to the marginally significantly higher rate of infant death among First Nations infants born to mothers living on-reserve. All three rates were much higher than the overall Canadian rates [31], so strategies to reduce infant deaths need to be directed to women living both on- and off-reserve. The most frequent causes of death in First Nations infants were congenital anomalies and SIDS, suggesting that strategies to promote preconception use of folic acid to prevent neural tube defects [32], and use of back-to-sleep campaigns and reduction of 
maternal smoking and exposure to environmental tobacco smoke to prevent SIDS may be useful [33]. Efforts to increase initiation and duration of breastfeeding may also be worthwhile, because exclusive breastfeeding for at least six months has been associated with up to a $50 \%$ reduction in SIDS [34]. The higher rates of infant death among First Nations births to mothers living on-reserve require additional consideration. Homes in Manitoba First Nations communities may have high levels of fungi, bacteria and air particulates that are associated with SIDS [35]. Efforts to improve living conditions and safety of homes on reserves may be beneficial.

Programs need to be implemented at the community level to ensure success. A program to increase breastfeeding rates at the community level was highly effective in one First Nations reserve [36]. Evaluations of programs have found that First Nations community involvement in program design, implementation, and evaluation improved participant satisfaction, promoted early access and participation in care, and enhanced women's health behaviors, resulting in improved nutrition and decreased tobacco and alcohol consumption [27].

\section{Strengths and Limitations}

This study is the first to examine differences in birth outcomes among First Nations births to women living on- and off-reserve, and was conducted in the Canadian province with the second highest concentration of First Nations people ( $8 \%$ of the population in 2001) [1], providing a large cohort of 26,176 First Nations births. However, our study also has limitations. We did not include stillbirths as a birth outcome because there were no First Nations identifiers on stillbirth registrations in Manitoba. Some First Nations mothers or fathers may not have reported First Nations status on birth registrations, resulting in misclassification of the birth as non-First Nations. We were only able to determine onreserve or off-reserve residence based on postal code (or municipality) of the usual place of residence as reported on the birth registration, so we were not able to assess changes in the mother's residence during the pregnancy, or subsequent to the birth. Further study would be needed to examine the effect of migration patterns and multiple moves throughout the pregnancy on birth outcomes. In addition, the residence of the mother during pregnancy is not necessarily the same as the place of childbirth. Many First Nations women from northern areas of the province in particular are relocated to Winnipeg for childbirth, and then return to the reserve, so initial neonatal care is often provided in a tertiary care hospital. The use of postal code to determine if a person is living on-reserve may result in misclassification in instances where some people may live close to, but not in, the First Nations community and would be grouped with "onreserve" despite living "off-reserve." Furthermore, the limitations of using on-reserve versus off-reserve as a geographic variable constructed to reflect residency status need to be considered. Future research should explore using more contextually rich variables such as remoteness and economic disparity to fully understand the differences between on- and off-reserve locations. In addition, there is a potential for onreserve differences due to north-south location, small versus medium versus large communities, transferred versus nontransferred births, and type of health centre on-reserve. Off- reserve populations may differ by rural versus small urban versus large urban settings.

Our study is largely descriptive; we were unable to assess potential causes of differences in outcomes between births to mothers living on- and off-reserve, because of lack of information on potential confounders or effect mediators in the Statistics Canada database. Factors such as maternal education, occupation, income, smoking, alcohol use, drug use, obesity, prenatal complications and prenatal care utilization may affect birth outcomes, yet we were unable to identify or control for these factors. Further research is needed to understand these mediating risk factors.

\section{SYNOPSIS}

For First Nations in Manitoba, living off-reserve was associated with higher rates of preterm, low birth weight and small-for-gestational-age birth, suggesting more attention needs to be given to provision of high quality prenatal care, while living on-reserve was associated with marginally higher rates of infant death, suggesting the need for strategies to improve infant care to reduce postneonatal mortality.

\section{ACKNOWLEDGEMENTS}

This study was supported by a research grant from the Canadian Institutes of Health Research (CIHR), Institute of Aboriginal Peoples' Health (IAPH) (grant \# 73551). We are grateful to Statistics Canada for providing access to the data for the research project, and to the Assembly of Manitoba Chiefs Health Information and Research Governance Committee for their support and feedback. Dr. Heaman was supported by a CIHR New Investigator award (2003-2008) and a CIHR Chair in Gender and Health award (2008-2013). Dr. Luo was supported by a Clinical Epidemiology Junior Scholar award from the Fonds de la Recherche en Santé du Québec (FRSQ) and a CIHR New Investigator Award, Dr. Smylie by a CIHR-IAPH Senior Research Fellowship and a CIHR New Investigator award, Dr. Martens by a CIHR New Investigator award and a CIHR/PHAC (Public Health Agency of Canada) Applied Public Health Chair award, Ms. Agnew by a CIHR Aboriginal Capacity and Developmental Research Environments (ACADRE) summer internship, and Dr. Fraser by a CIHR Canada Research Chair award. Russell Wilkins (Health Analysis Division, Statistics Canada) reviewed the data and suggested revisions to the methods and results sections of this paper. Other members of the research group include Nancy GL McHugh, First Nations of Quebec and Labrador Health and Social Services Commission, Elena Labranche, Nunavik Regional Board of Health and Social Services, Catherine Carry, National Aboriginal Health Organization, Katherine Minich, University of Toronto, and Donna Lyon, National Aboriginal Health Organization.

\section{REFERENCES}

[1] Statistics Canada. 2001 Census: Analysis series. Aboriginal Peoples of Canada: A demographic profile. 2003. Available from http://www12.statcan.gc.ca/english/census01/products/analytic/co mpanion/abor/pdf/96F0030XIE2001007.pdf. Accessed September $21,2009$.

[2] Hallett B. Aboriginal People in Manitoba. Winnipeg, Manitoba: Manitoba Government; 2006.

[3] Norris MJ, Clatworthy S. Aboriginal mobility and migration within urban Canada: Outcomes, factors and implications. In: Newhouse D, Peters E, Eds. Not Strangers in These Parts - Urban Aboriginal 
Peoples. Ottawa: Policy Research Initiative, Government of Canada; 2003; 51-78.

[4] Cooke M, Belanger D. Migration theories and First Nations mobility: Towards a systems perspective. Canadian Review of Sociology and Anthropology-Revue Canadienne de Sociologie et D Anthropologie 2006; 43(2): 141-64.

[5] Cooke M. The effects of personal characteristics on migration from prairie cities to First Nations. Canadian Ethnic Studies 2002; 34(2): 40-62.

[6] Ontario Native Women's Association. Breaking free: A proposal for change to Aboriginal family violence. Thunder Bay, 1989.

[7] Tomashek KM, Qin C, Hsia J, Iyasu S, Barfield WD, Flowers LM. Infant mortality trends and differences between American Indian/Alaska Native infants and white infants in the United States, 1989-1991 and 1998-2000. Am J Public Health 2006; 96(12): 2222-7.

[8] Freemantle CJ, Read AW, de Klerk NH, McAullay D, Anderson IP, Stanley FJ. Patterns, trends, and increasing disparities in mortality for Aboriginal and non-Aboriginal infants born in Western Australia, 1980-2001: population database study. Lancet 2006; 367: 1758-66.

[9] Luo ZC, Kierans WJ, Wilkins R, Liston RM, Uh SH, Kramer MS. Infant mortality among First Nations versus non-First Nations in British Columbia: temporal trends in rural versus urban areas, 1981-2000. Int J Epidemiol 2004; 33(6): 1252-9.

[10] Luo ZC, Wilkins R, Platt RW, Kramer MS. Risks of adverse pregnancy outcomes among Inuit and North American Indian women in Quebec, 1985-97. Paediatr Perinat Epidemiol 2004; 18(1): 40-50.

[11] Baldwin LM, Grossman DC, Casey S, et al. Perinatal and infant health among rural and urban American Indians/Alaska Natives. Am J Public Health 2002; 92(9): 1491-7.

[12] Grossman DC, Baldwin LM, Casey S, Nixon B, Hollow W, Hart LG. Disparities in infant health among American Indians and Alaska natives in US metropolitan areas. Pediatrics 2002; 109(4): 627-33.

[13] Alessandri LM, Chambers HM, Blair EM, Read AW. Perinatal and postneonatal mortality among Indigenous and non-Indigenous infants born in Western Australia, 1980-1998. Med J Aust 2001; 175(4): 185-9.

[14] Johnson D, Jin Y, Truman C. Influence of aboriginal and socioeconomic status on birth outcome and maternal morbidity. J Obstet Gynaecol Can 2002; 24(8): 633-40.

[15] Indigenous children's health report: Health assessment in action. Smylie J, Adomako P, editors. 2009. Toronto, ON, The Centre for Research on Inner City Health.

[16] Luo ZC, Senecal S, Simonet F, Guimond E, Penney C, Wilkins R. Birth outcomes in the Inuit-inhabited areas of Canada. CMAJ 2010; 182(3): 235-42.

[17] Fair M, Cyr M, Allen AC, Wen SW, Guyon G, MacDonald RC. An assessment of the validity of a computer system for probabilistic record linkage of birth and infant death records in Canada. The Fetal and Infant Health Study Group. Chronic Dis Can 2000; 21(1): 8-13.

[18] Kramer MS, Liu S, Luo Z, Yuan H, Platt RW, Joseph KS. Analysis of perinatal mortality and its components: time for a change? Am J Epidemiol 2002; 156(6): 493-7.

[19] Kramer MS, Platt RW, Wen SW, et al. A new and improved population-based Canadian reference for birth weight for gestational age. Pediatrics 2001; 108(2): E35.
[20] Cole S, Hartford RB, Bergsjo P, McCarthy B. International collaborative effort (ICE) on birth weight, plurality, perinatal and infant mortality. III: A method of grouping underlying causes of infant death to aid international comparisons. Acta Obstet Gynecol Scand 1989; 68: 113-7.

[21] Guntheroth WG, Spiers PS. The triple risk hypotheses in sudden infant death syndrome. Pediatrics 2002; 110(5): e64.

[22] Wenman WM, Joffres MR, Tataryn IV. A prospective cohort study of pregnancy risk factors and birth outcomes in Aboriginal women. CMAJ 2004; 171(6): 585-9.

[23] Heaman MI, Chalmers K. Prevalence and correlates of smoking during pregnancy: a comparison of aboriginal and non-aboriginal women in manitoba. Birth 2005; 32(4): 299-305.

[24] Heaman MI, Blanchard JF, Gupton AL, Moffatt ME, Currie RF Risk factors for spontaneous preterm birth among Aboriginal and non-Aboriginal women in Manitoba. Paediatr Perinat Epidemiol 2005; 19(3): 181-93.

[25] Heaman MI, Gupton AL, Moffatt ME. Prevalence and predictors of inadequate prenatal care: a comparison of aboriginal and nonaboriginal women in Manitoba. J Obstet Gynaecol Can 2005; 27(3): 237-46.

[26] Hiebert S. The utilization of antenatal services in remote Manitoba First Nations communities. Int J Circumpolar Health 2001; 60(1): 64-71.

[27] Smith D, Edwards N, Varcoe C, Martens PJ, Davies B. Bringing safety and responsiveness into the forefront of care for pregnant and parenting aboriginal people. ANS Adv Nurs Sci 2006; 29(2): E27-E44.

[28] Caulfield LE, Harris SB, Whalen EA, Sugamori ME. Maternal nutritional status, diabetes and risk of macrosomia among Native Canadian women. Early Hum Dev 1998; 50(3):293-303.

[29] Aljohani N, Rempel BM, Ludwig S, et al. Gestational diabetes in Manitoba during a twenty-year period. Clin Invest Med 2008; 31(3): E131-E137.

[30] Aljohani N, Rempel BM, Ludwig S, et al. Impact of diabetes on maternal-fetal outcomes in Manitoba: Relationship with ethnic and environmental factors. Clin Invest Med 2008; 31(6): E338-E345.

[31] Public Health Agency of Canada. Canadian Perinatal Health Report, 2008 Edition. 2008. Ottawa, Public Health Agency of Canada.

[32] Public Health Agency of Canada. Folic acid and prevention of neural tube defects. Information update from PHAC - 2008. Available from: URL:http://www.phac-aspc.gc.ca/fa-af/fa-af08eng.php. Accessed October 12, 2009.

[33] Gunn AJ, Gunn TR, Mitchell EA. Is changing the sleep environment enough? Current recommendations for SIDS. Sleep Med Rev 2000; 4(5): 453-69.

[34] Vennemann NM, Bajanowski T, Brinkmann B, et al. Does breastfeeding reduce the risk of sudden infant death syndrome? Pediatrics 2009; 123(3): e406-e410.

[35] Wilson CE. Sudden infant death syndrome and Canadian Aboriginals: bacteria and infections. FEMS Immunol Med Microbiol 1999; 25(1-2): 221-6.

[36] Martens PJ. Increasing breastfeeding initiation and duration at a community level: an evaluation of Sagkeeng First Nation's community health nurse and peer counselor programs. J Hum Lact 2002; 18(3): 236-46.

(C) Heaman et al.; Licensee Bentham Open.

This is an open access article licensed under the terms of the Creative Commons Attribution Non-Commercial License (http://creativecommons.org/licenses/by-nc/3.0/) which permits unrestricted, non-commercial use, distribution and reproduction in any medium, provided the work is properly cited. 